\title{
Development of Models for the Rational Design of Different Shapes of Pit Latrine
}

\author{
Ugwu Francis ifeuzu, Agunwamba Jonah Chukwuemeka
}

\begin{abstract}
Specific models for the rational design of pit latrines of different shapes and sizes are presently non-existent. What exist are general design models irrespective of the shape and size of latrine which may not give the actual design parameters needed. This research was limited to the derivation of models that will aid the design of the capacity of pit latrines of different shapes and dimensions for different population of users and under different soil formations and ground conditions. The objective of this research was to derive models for the rational design of pit latrines of different shapes using data collected from 500 different household pit latrines already filled up. Thus, models were derived for different latrine pit shapes and sizes using data collected through the administration of designed questionnaire on 500 households having pit latrines already filled up. Models were developed specifically for different latrine shapes whereas those of other researchers were generalized. These models were calibrated and verified for the rational design of pit latrines of different shapes and sizes. The regression coefficients for calibration were $0.75,0.65$, and 0.50 and for verification are $0.97,0.98$ and 0.99 for square, circular and rectangular pits respectively. The implication of this research is availability of design models for the construction of different pit latrine shapes.
\end{abstract}

Keywords: Ordinary Pit Latrines; Pit Latrine Sludge; Rational Design Of Pit Latrine Shapes; Regression Coefficient For Calibration; Regression Coefficient For Calibration; Coefficient Of Correlation; Coefficient Of Verification..

\section{INTRODUCTION}

Lack of access to basic sanitation and safe water supply facilities is a major cause of diseases and infant mortality in developing countries. Approximately 2.6 billion people worldwide lack improved access to basic sanitation with the largest part residing in Africa and Asia. Safe disposal of excreta has constituted one of the environmental problems facing mankind. Unsafe disposal of excreta is one of the major sources of parasitic diseases causing untold hardship to the populace both economically, socially and health wise. Consequently around the world, there is a drive to ensure the provision of safe and adequate sanitation and water supply facilities. In line with this, MDG 7 target is to reduce the number of people without access to basic sanitation by half by the year 2015 .

\footnotetext{
Manuscript received on 29 March 2021 | Revised Manuscript received on 14 April 2021 | Manuscript Accepted on 15 May 2021 | Manuscript published on 30 May 2021. * Correspondence Author

Ugwu Francis ifeuzu*, Department of Civil Engineering, University of Nigeria, Nsukka. E-mail:ugwufrancisifeuzu@yahoo.com

Prof. Agunwamba Jonah Chukwuemeka, Department of Civil Engineering, University of Nigeria, Nsukka. E-mail: Jonah.Agunwamba@unn.edu.ng

(C) The Authors. Published by Lattice Science Publication (LSP). This is an open access article under the CC-BY-NC-ND license (http://creativecommons.org/licenses/by-nc-nd/4.0/)
}

Since there was no existing model for the design of different shapes of pit latrine, this study has provided such to enable households construct the type of latrine system they need based on affordability and space available.

The objectives of this research wereto collect data from 500 households on different latrines with respect to their sizes and shapes, population of users, lifespan of already filled pits, soil type and ground conditions and frequency of usage by household members; collect data on the geometry, soil-seal depth from existing pit latrines; develop a model for designing pit latrines under different soil types and ground conditions, calibrate and verify the models using field data.

As a contribution to providing improved basic and sustainable sanitation services especially to households of semi-urban and rural areas, this research sought to find solutions to the problems attendant with latrine construction through the derivation of accurate models using both field data for the design. Such models will assist families to decide on a particular latrine technology that will serve them for longer periods.

\section{LITERATURES REVIEW}

There are several forms of pit latrine and are classified as direct, offset or partly offset. The most appropriate type of pit latrine depends on local situation, including the level of groundwater, traditions and culture of the users. The material for anal cleansing is particularly important and may be water or it may be solid material such as leaves, grass or corncobs. Basically, any pit latrine is made up of two component parts namely the substructure and the superstructure. The substructure contains the absorption system that determines the functionality and lifespan of the pit latrine depending on the type of soil and the ground conditions, population of the users, design life and the sludge accumulation rate. The superstructure contributes to the increase in lifespan of the pit latrine. The main function of the pit, apart from serving as reservoir of the faecal matter, is to treat and filter the effluent into the ground. The extent to which this is achieved depends on the infiltrative capacity of the soil.

The pit should provide capacity for the accumulation of solids and must be large enough for infiltration of the liquid into the surrounding soil. In sizing the pit, the sludge accumulation rate is determined. The volume of the waste expected is based on the population of the household and the volume is determined by the type of soil and groundwater conditions, population of users, design capacity and the sludge accumulation rate.

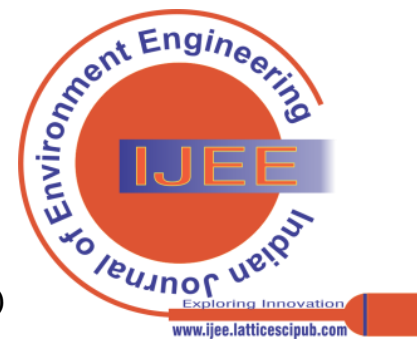


The shape of the pit influences the velocity of flow through it, the depth of accumulation of sludge, and the presence or absence of stagnant corners.

Due to the emergence of latrines of different types and shapes in the peri-urban and rural areas of most countries including Nigeria, Engineers have deemed it necessary to come up with designs that will direct households to build latrines that will not constitute environmental hazards. There has been increasing emphasis on households to adopt one latrine shape or the other to suit their needs based on affordability and available space. This means that the latrine option and dimensions must be able to give them the maximum service they want depending on the number of users, soil structure, cost and other local factors, etc.

Based on the popularity of ordinary pit latrines attested by their increasing adoption in rural and semi-urban settlements, this research therefore is relevant as it seeks to derive more accurate and reliable models for the design of pit latrine volume for different shapes of latrines for both rural and semi-urban dwellers using data generated from the field and the laboratory.

There are factors that have to do with the functioning of the pits so designed. These include the characteristics of the surrounding soil. Geological characteristics of the surrounding soil where the pit latrines are placed can have an important influence in the processes happening inside the pit (Bhagwan et al., 2008). These are the type of soil/rock. The porosity of the soil will determine the leaching and draining process that will occur in the pit. This will affect the liquid water level and moisture contents, as well as potentially influences diffusion of soluble components in or out of the pit, and hence microbial metabolism. It may also affect decomposition through the alteration of the ecosystem in the pit. Soil microflora and microfauna (higher organisms such as protozoa, metazoan and worms) may move into the pit from the surrounding soil and contribute to decomposition of organic material. Moreover, the permeability of the soil determines the functionality of the pit latrine. Loose soil like sandy soil is highly permeable and has a long fill-up time. The soil permeability, which depends on soil type, the particle size distribution and the relative compaction of the soil, is the primary determinant of the absorption capacity of the soil.

As well as providing sufficient capacity for the accumulation of solids, a pit must be large enough for infiltration of the liquid into the surrounding soil. Also, in sizing the pit, the sludge accumulation rate is determined. The volume of the waste expected is based on the population of the household and the volume (the dimensions not withstanding) is determined by the type of soil and groundwater conditions, population of users, design capacity and the sludge accumulation rate. The volume of faeces expected will be determined with a view to sizing the pit latrine.

\subsection{Theory and Design Considerations Of Pit Latrine Systems}

To minimize health risks, the soil mantle must be able to accept and transmit human waste (pollutants) such as faeces and other by-products of body metabolism such that surfacing of effluent does not occur and microorganisms are rapidly eliminated from ground flows. Proper design of a soil absorption system requires an understanding of the rate of movement of water out of the trench and also through the soil mantle.

\subsubsection{General Design Considerations}

2.1.2 Design Population: The population of users is very important in the design of the pit system as it will determine the pit volume and the lifespan as the fill-up time depends on this factor.

\subsubsection{Type of Anal Cleansing Materials Used}

The material used for anal cleansing after defecation is particularly important. It may be water or it may be bulky solid material such as corncobs, sticks or stone which obviously makes the pit fill up more quickly as against the use of paper, leaves and grasses

\subsubsection{Sludge Accumulation Ratio.}

The average capacity is known as the solid accumulation ratio. The value depends on the type of anal cleansing materials as leaves, grasses and corncobs. The values of the sludge accumulation ratios to be taken are as follows:

(i) 40 litres/person/year if water is used for anal cleansing and the pit is wet;

(ii) 60 litres/person/year if the pit is dry, or if solid material such as grass, corncobs or

Newspaper is used for anal cleansing;

(iii) 90 litres/person/year if solid anal cleansing material is used in a dry pit.

This varied from place to place since sludge accumulation depends on factors like temperature and the type of sewage. For example, at Nsukka, the value is $0.04 \mathrm{~m}^{3} /$ person/year. The accumulation rate appears to decrease with increasing number of users. However, the accumulation rate does decrease as the pit fills (i.e. the rate of filling slows with time)

\subsubsection{Expected Lifespan of the pit}

This is the period of time for which the pit latrine can function satisfactorily with little or no problem. To estimate the length of time during which the pit will serve satisfactorily, soil factors and ground conditions are often taken into consideration. The pit should be put out of use when solid is $0.5 \mathrm{~m}$ below the top slab.

$$
\begin{aligned}
& \text { Lifespan of pit }=\frac{\text { Volume of pit }}{\text { pludge accumulation. rate } \mathrm{x}} \\
& \text { population }
\end{aligned}
$$

\subsubsection{The Pit Volume}

The size of a pit latrine is determined by the intending number of users, the expected lifespan and the solid accumulation ratio (design capacity). The relationship between the pit volume and other parameters can be expressed as:

$$
\mathrm{V} \alpha \mathrm{CPN}
$$

or

$$
\mathrm{V}=\alpha_{0} \mathrm{CPN}
$$


where $\mathrm{V}$ is the volume of the pit latrine in $\mathrm{m}^{3}, \mathrm{C}$ is the design capacity in $\mathrm{m}^{3} / \mathrm{per} / \mathrm{day}$, $\mathrm{P}$ is the intended number of users and $\mathrm{N}$ is the design life of the pit or frequency of emptying (if applicable) in years while $\alpha_{0}$ is the proportionality constant and the value depends on the material used for anal cleansing.

\subsection{Previous Works on Pit Latrine Design Model}

\subsubsection{Design Models for VIP Latrine}

In their design for pit latrine (Oluwafemi, 1984) pit size should be determined by the design capacity or the solid accumulation rate, number of users, the number of years of service intended and the soil conditions. This is shown by the relationship,

$$
\mathrm{V}=1.25 \mathrm{CPN}
$$

where $\mathrm{V}$ is the volume of pit less than $12 \mathrm{ft}$ deep, $\mathrm{C}$ is the design capacity in $\mathrm{ft}^{3}$ /person/year, $\mathrm{P}$ is the number of is to be used before emptying. They established that the average capacity as $1.1 \mathrm{ft}^{3} /$ person/year if grass, corncob or leaves is used for anal cleansing. The factor, 1.25 is introduced since the pit is filled in with earth or emptied when $3 / 4$ full. For wet pit, the effective solid accumulation rate should be $1.3 \mathrm{ft}^{3} /$ person/year and for dry pit, it should be increased to $2 \mathrm{ft}^{3} /$ person/year.

In another version, a NGO commissioned by UNICEF (CASSAD, 2005) established that the effective pit volume depends on the solid accumulation rate, number of users and the design life. A free space of $0.5 \mathrm{~m}$ is allowed at the top and the pit put out of use but from field data collected, most of the free spaces were $0.5 \mathrm{~m}$ and below thereby negating model below. In its work, he researcher established that the effective pit volume space, $\mathrm{V}\left(\mathrm{m}^{3}\right)$ of pit less than $4 \mathrm{~m}$ deep may be calculated from the equation

$$
\mathrm{V}=\mathrm{CPN}
$$

Where $\mathrm{C}$ is the solid accumulation ratio in $\mathrm{m}^{3}$ /person/year, $\mathrm{P}$ is the population of users and $\mathrm{N}$ is the lifespan of the pit in years. For dry pit, the solid accumulation ratio is between $0.04-0.05 \mathrm{~m}^{3} / \mathrm{per} / \mathrm{yr}$ and for wet pit, it is $0.02-0.03 \mathrm{~m}^{3} / \mathrm{per} / \mathrm{yr}$. The factor, 1.25 is introduced if bulky material is used for anal cleansing and the pit emptied when $3 / 4$ full.

\subsubsection{Ordinary Pit Latrine}

In the case of ordinary pit latrine, the size of the pit is determined by the intending number of users, number of years of service intended and soil conditions.

The pit volume is calculated using the formula

$$
\mathrm{V}=1.33 \mathrm{PCN}
$$

WhereV is the volume of the pit less than $4 \mathrm{~m}$ deep in $\mathrm{m}^{3}$, C is the pit design capacity in $\mathrm{m} 3 /$ capita/year (or the sludge accumulation ratio), $\mathrm{P}$ is the intended number of users and $\mathrm{N}$ is the design life of the pit.Maximum recommended pit depth is $4 \mathrm{~m}$ to avoid groundwater pollution.

The capacity of dry pit (pit that does not extend below the groundwater table) is usually taken as $0.06 \mathrm{~m} 3 / \mathrm{capita} /$ year. If non-degradable materials such as corn cobs, cement bags are used for anal cleansing, this people using the latrine and $\mathrm{N}$ is the number of years the pit

value should be increased by $50 \%$.For wet pits, the capacity should be $0.04 \mathrm{~m}^{3} / \mathrm{capita} /$ year. Accumulation rates are lower in wet pits because biodegradation is faster under wet conditions than in the only just moist conditions in dry pits. In another version, an NGO commissioned by UNICEF (CASSAD, 2005) established that the effective pit volume depends on the solid accumulation rate, number of users and the design life. A free space of $0.5 \mathrm{~m}$ is allowed at the top and the pit put out of use but from field data collected, most of the free spaces were $0.5 \mathrm{~m}$ and less thereby negating model below. In its work, the researcher established that the effective pit volume space, $\mathrm{V}\left(\mathrm{m}^{3}\right)$ of pit less than $4 \mathrm{~m}$ deep may be calculated from the equation

$$
\mathrm{V}=\mathrm{CPN}
$$

Where $\mathrm{C}$ is the solid accumulation ratio in $\mathrm{m}^{3} /$ person/year, $\mathrm{P}$ is the population of users and $\mathrm{N}$ is the lifespan of the pit in years. For dry pit, the solid accumulation ratio is between $0.04-0.05 \mathrm{~m}^{3} / \mathrm{per} / \mathrm{yr}$ and for wet pit, it is $0.02-0.03 \mathrm{~m}^{3} / \mathrm{per} / \mathrm{yr}$. The factor, 1.25 is introduced if bulky material is used for anal cleansing and the pit emptied when $3 / 4$ full.

\section{MATERIALS AND METHOD}

In this research, the following approaches were adopted for data collection and analyses

\subsection{Field Visits and Use of Questionnaire}

\subsubsection{Questionnaire Administration to 500 Households.}

To achieve this, a household questionnaire was designed and approved by my Supervisor, and administered in 500 households (based on random sampling technique) of Aku Community in Igbo-Etiti LGA of Enugu State. The questions were such that any member of the household from ages of 15 years and above could answer them. Data such as household population, frequency of defecation, time of fillup of pits formerly in use, soil type and ground conditions, anal cleansing materials, type of food taken by users, etc were collected and documented. The hygiene level of the latrines was observed as to evaluate the user-behaviour. This helped to know whether the users throw wastes (sullage/dirty water or solid wastes from sweepings) into the pit or not as these would affect the filling rate of the pit latrine).

\subsubsection{Physical Field Measurements}

Physical measurement made during the questionnaire administration was the soil-seal depth of the faeces, i.e. free space between the top of the latrine sludge and the latrine squatting device of the already filled latrine. Other measurements included the dimensions and shapes of the pit latrines.

\subsubsection{Analysis of the Questionnaire data}

Data for the different latrine shapes were collected and the average values determined. The regression equations were obtained to see how the data relate with one another.

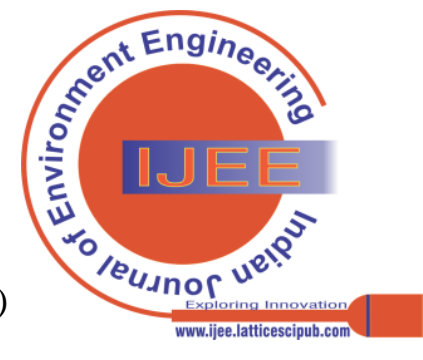


Moreover, the correlation coefficients of the data collected were calculated to ensure that one was on track. In addition figures were drawn to see how one variable relates with another.

\subsubsection{Verification and Calibration of Models}

Well-calibrated and verified model for rational design of pit latrine of different shapes such as square, rectangular and circular shapes were derived using data obtained from the questionnaires administered on households.

\subsection{Derivation of Models for the Rational Design of Pit} Latrines.

$$
\begin{aligned}
& \sum \operatorname{InV}=\operatorname{In} \alpha_{0}+\alpha_{1} \sum \operatorname{InC}+\alpha_{2} \sum \operatorname{In} \mathrm{P}+\alpha_{3} \sum \operatorname{InN} \\
& \sum \operatorname{InV} \sum \operatorname{InC}=\operatorname{In} \alpha_{0} \sum \operatorname{InC}+\alpha_{1}\left(\sum \operatorname{InC}\right)^{2}+\alpha_{2} \sum \operatorname{InP} \sum \operatorname{InC}+\alpha_{3} \sum \operatorname{InN} \sum \operatorname{InC} \\
& \sum \operatorname{InV} \sum \operatorname{InP}=\operatorname{In} \alpha_{0} \sum \operatorname{InP}+\alpha_{1} \sum \operatorname{InC} \sum \operatorname{InP}+\alpha_{2}\left(\sum \operatorname{InP}\right)^{2}+\alpha_{3} \sum \operatorname{InN} \sum \operatorname{InP} \\
& \sum \operatorname{InV} \sum \operatorname{InN}=\operatorname{In} \alpha_{0} \sum \operatorname{InN}+\alpha_{1} \sum \operatorname{InC} \sum \operatorname{InN}+\alpha_{2} \sum \operatorname{InP} \sum \operatorname{InN}+\alpha_{3}\left(\sum \operatorname{InN}\right)^{2}
\end{aligned}
$$

The various pit latrine models can be derived using empirical formula.

Recalling Equation 2 we have:

$$
\text { or } \mathrm{V}=\alpha_{0} \mathrm{CPN}
$$

The parameters have earlier been defined.

$\operatorname{InV}=\operatorname{In} \alpha_{0}+\alpha_{1} \operatorname{InC}+\alpha_{2} \operatorname{InP}+\alpha_{3} \operatorname{InN}$

\subsection{Correlation Coefficient for the Data Obtained}

Correlation coefficients for the data obtained from the field for the three different pit latrine shapes were calculated using the formula below. This was to see the reliability of the data so collected.

Coefficient. of correlation,

$r=\frac{\left[\left(n \sum x y-\sum x \sum y\right)\right]^{2}}{\left[\left(n \sum x^{2}-\left(\sum x\right)^{2}\right)\left(n \sum y^{2}-\left(\sum y\right)^{2}\right]\right.}$

where $r$ is the coefficient of correlation, $x$ is the population in persons, $\mathrm{m}$ is the gradient, $\mathrm{c}$ is the intercept on $\mathrm{y}$-axis, $\mathrm{y}$ is the filling rate in $\mathrm{m}^{3}$ /person and $\mathrm{n}$ is the life span of the pit latrine. Using the Equations 3.1, 3.2 and 3.4 and the data for square, circular and rectangular pit latrines as collected from the field, the gradients, intercepts and the correlation coefficients as well as the regression equations were obtained accordingly and summarized below.
Table 3.2 :Summary of Parameters obtained.for the Three Different Pits.

\begin{tabular}{|l|c|c|}
\hline Latrine type & Coefficient of Correlation, $\mathrm{r}$ & $\mathrm{r}^{2}$ \\
\hline Square pit & 0.75 & 0.56 \\
\hline Circular pit & 0.65 & 0.42 \\
\hline Rectangular pit & 0.50 & 0.25 \\
\hline
\end{tabular}

\subsection{Derivation of Pit Latrine Design Models}

The design volume of the pit was conceptualize

$$
\mathrm{V}=\alpha_{0} \mathrm{C}^{\alpha 1} \mathrm{P}^{\alpha 2} \mathrm{~N}^{\alpha 3}
$$

where $\mathrm{v}$ is the volume in $\mathrm{m} 3, \mathrm{C}$ is the sludge accumulation ratio in $\mathrm{m} 3 /$ pers/yr, $\mathrm{P}$ is the

population of users in persons and $\mathrm{N}$ is the lifespan of the pit in years while $\alpha 0, \alpha 1, \alpha 2$ and $\alpha 3$ are constants.

Linearizing Equation 3.5 we have:

$\operatorname{InV}=\operatorname{In} \alpha_{0}+\alpha_{1} \operatorname{InC}+\alpha_{2} \operatorname{InP}+\alpha_{3} \operatorname{InN}$

The Multiple Regression Analysis from Equation 11 gives

$$
\begin{aligned}
& \sum \operatorname{InV}=\operatorname{In} \alpha_{0}+\alpha_{1} \sum \operatorname{InC}+\alpha_{2} \sum \operatorname{In} \mathrm{P}+\alpha_{3} \sum \operatorname{InN} \\
& \sum \operatorname{InV} \sum \operatorname{InC}=\operatorname{In} \alpha_{0} \sum \operatorname{InC}+\alpha_{1}\left(\sum \operatorname{InC}\right)^{2}+\alpha_{2} \sum \operatorname{InP} \sum \operatorname{InC}+\alpha_{3} \sum \operatorname{InN} \sum \operatorname{InC} \\
& \sum \operatorname{InV} \sum \operatorname{InP}=\operatorname{In} \alpha_{0} \sum \operatorname{InP}+\alpha_{1} \sum \operatorname{InC} \sum \operatorname{InP}+\alpha_{2}\left(\sum \operatorname{InP}\right)^{2}+\alpha_{3} \sum \operatorname{InN} \sum \operatorname{InP} \alpha_{3} \sum \operatorname{InP} \\
& \sum \operatorname{InV} \sum \operatorname{InN}=\operatorname{In} \alpha_{0} \sum \operatorname{InN}+\alpha_{1} \sum \operatorname{InC} \sum \operatorname{InN}+\alpha_{2} \sum \operatorname{InP} \sum \operatorname{InN}+\alpha_{3}\left(\sum \operatorname{InN}\right)^{2}
\end{aligned}
$$

Substitution of the values in Tables 1-3 into these multiple regression equations

led to the computation of the constants which gave the regression equations below. Subsequently,

the models for the rational design of the three latrine shapes were derived, verified and calibrated.

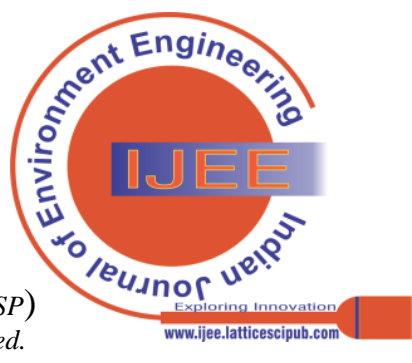


Table 1: Square Pits Data

\begin{tabular}{|c|c|c|c|c|c|c|c|c|c|}
\hline Pop. & $\operatorname{lnP}$ & Vol.(m3) & $\operatorname{lnV}$ & $\begin{array}{l}\text { Time } \\
\text { Full } \\
\text { (Yrs),N }\end{array}$ & $\ell \mathrm{nN}$ & $\begin{array}{c}\text { Filling } \\
\text { Rate } \\
\left(\mathrm{m}^{3} / \text { per }\right), \mathbf{R}\end{array}$ & $\operatorname{lnR}$ & $\begin{array}{c}\text { Sludge Accu. } \\
\text { Ratio(m/3/pers/day),C }\end{array}$ & $\operatorname{lnC}$ \\
\hline 3 & 1.1 & 25.74 & 3.25 & 32.33 & 3.48 & 6.42 & 1.86 & 0.27 & -1.61 \\
\hline 4 & 1.39 & 37.05 & 3.61 & 30.5 & 3.42 & 5.6 & 1.72 & 0.3 & -1.43 \\
\hline 5 & 1.61 & 13.89 & 2.63 & 24.83 & 3.21 & 2.71 & 1 & 0.11 & $\begin{array}{l}-2.3 \\
\end{array}$ \\
\hline 6 & 1.79 & 17.13 & 2.84 & 28.75 & 3.36 & 2.6 & 0.96 & 0.1 & $\begin{array}{l}-2.41 \\
\end{array}$ \\
\hline 7 & 1.95 & 25.73 & 3.25 & 26.13 & 3.26 & 3.92 & 1.37 & 0,14 & -2.04 \\
\hline 8 & 2.08 & 21.43 & 3.06 & 25.8 & 3.25 & 2.62 & 0.96 & 0.1 & -2.41 \\
\hline 9 & 2.2 & 15.04 & 2.78 & 27.86 & 3.33 & 2.27 & 0.82 & 0.06 & -2.81 \\
\hline 10 & 2.3 & 17.16 & 2.84 & 25.14 & 3.22 & 2.22 & 0.8 & 0.07 & -2.66 \\
\hline 11 & 2.4 & 26.61 & $\begin{array}{l}3.28 \\
\end{array}$ & 27.2 & 3.3 & 2.5 & 0.92 & 0.07 & -2.66 \\
\hline 12 & 2.48 & 12.61 & 2.53 & 23 & 3.14 & 1.55 & 0.44 & 0.05 & -3 \\
\hline 13 & 2.56 & 38.26 & 3.64 & 33 & 3.5 & 0.85 & $\begin{array}{c}-0.16 \\
\end{array}$ & 0.07 & $\begin{array}{l}-2.66 \\
\end{array}$ \\
\hline 14 & 2.64 & 9.82 & 2.28 & 26.5 & 3.28 & 1.16 & 0.15 & 0.03 & -3.51 \\
\hline 15 & 2.71 & 15.64 & 2.75 & 23.5 & 3.16 & 1.1 & 0.95 & 0.04 & -3.22 \\
\hline $\bar{\Sigma}$ & 27.21 & & 38.74 & & 42.91 & & 11.79 & & -32.72 \\
\hline
\end{tabular}

Table 2. Circular Pits Data

\begin{tabular}{|c|c|c|c|c|c|c|c|c|c|}
\hline Pop. $\mathbf{P}$ & $\operatorname{lnP}$ & $\begin{array}{l}\text { Vol.(m3) } \\
\text { V }\end{array}$ & $\operatorname{lnV}$ & $\begin{array}{l}\text { Time Full } \\
\text { (Yrs), } \mathbf{N}\end{array}$ & $\overline{l n N}$ & $\begin{array}{l}\text { Filling } \\
\text { Rate } \\
\left(\mathrm{m}^{3} / \text { per), }\right. \\
\mathbf{R}\end{array}$ & $\overline{l n R}$ & $\begin{array}{l}\text { Sludge Accu. } \\
\text { Ratio } \\
\text { (m³/pers/day),C }\end{array}$ & $\overline{l n C}$ \\
\hline 3 & 1.1 & 16.44 & 2.8 & 29 & 3.37 & 5.17 & 1.64 & 0.18 & -1.71 \\
\hline 4 & 1.39 & $\begin{array}{l}42.51 \\
\end{array}$ & 3.75 & 18.5 & 2.92 & 8.8 & 2.17 & 0.52 & -0.65 \\
\hline 5 & 1.61 & 30.41 & 3.41 & 20.63 & 3.03 & 4.29 & 1.46 & 0.25 & -1.39 \\
\hline 6 & 1.79 & 43.23 & 3.77 & $\overline{22}$ & $\begin{array}{l}3.09 \\
\end{array}$ & 4.94 & 1.6 & 0.27 & -1.31 \\
\hline 7 & 1.95 & 23 & 3.14 & 28.5 & 3.35 & 2.02 & 0.7 & 0.09 & -2.41 \\
\hline 8 & 2.08 & 24.46 & 3.2 & 25.75 & 3.25 & 1.71 & 0.54 & 0.09 & -2.41 \\
\hline 9 & 2.2 & 23.38 & 3.15 & 17.33 & 2.85 & 1.43 & 0.36 & 0.11 & -2.21 \\
\hline 10 & 2.3 & 34.49 & 3.54 & 25.22 & 3.23 & 1.75 & 0.56 & 0.1 & -2.3 \\
\hline 11 & 2.4 & 38.49 & 3.65 & 20.5 & 3.02 & 1.6 & 0.47 & 0.12 & -2.12 \\
\hline 12 & 2.48 & 16.15 & 2.78 & 30.25 & 3.41 & 0.72 & -0.33 & 0.03 & -3.51 \\
\hline 13 & 2.56 & 36.49 & 3.6 & 23.75 & 3.17 & 1.07 & 0.07 & 0.08 & -2.53 \\
\hline 14 & 2.64 & 34.16 & 3.53 & 17.75 & 2.88 & 1.03 & 0.03 & 0.09 & -2.41 \\
\hline 15 & 2.71 & \begin{tabular}{|l|l|}
5.28 \\
\end{tabular} & 3.56 & 19 & 2.94 & 1.03 & 0.03 & 0.08 & -2.53 \\
\hline$\sum$ & 27.21 & & 43.88 & & 40.51 & & $\begin{array}{c}\sum \operatorname{InnR} \\
9.3\end{array}$ & & $\begin{array}{c}\sum \operatorname{lnC} \\
-27.49\end{array}$ \\
\hline
\end{tabular}

Table 3: Rectangular Pits Data

\begin{tabular}{|c|c|c|c|c|c|c|c|c|c|}
\hline Pop,P & $\operatorname{lnP}$ & $\begin{array}{l}\text { Vol.(m3) } \\
\mathbf{v}\end{array}$ & $\operatorname{lnV}$ & $\begin{array}{l}\text { Time } \\
\text { Full } \\
\text { (Yrs) } \\
\mathbf{N}\end{array}$ & $\operatorname{lnN}$ & $\begin{array}{l}\text { Filing } \\
\text { Rate } \\
\text { (m³/pers) } \\
\quad \quad \mathbf{R}\end{array}$ & $\ell \mathrm{nR}$ & $\begin{array}{l}\text { SludgeAcc..Ratio } \\
\text { (m³/pers/da) C }\end{array}$ & $\operatorname{lnC}$ \\
\hline 1 & 0 & 18.16 & 2.9 & 44 & $\begin{array}{l}3.78 \\
\end{array}$ & 20.8 & 3.03 & 0.43 & $\begin{array}{l}-0.8 \\
\end{array}$ \\
\hline 2 & 0.69 & 15.68 & 2.75 & 23.33 & 3.15 & 8.87 & 2.18 & 0.35 & -1.02 \\
\hline 3 & 1.1 & 17.09 & 2.84 & 29.67 & 3.39 & 6.49 & 1.87 & 0.2 & -1.56 \\
\hline 4 & 1.39 & 22.08 & 3.09 & 23 & 3.14 & 6.2 & 1.82 & 0.25 & -1.35 \\
\hline 5 & 1.61 & 17.82 & 2.88 & 24.75 & 3.21 & 4.3 & 1.46 & 0.15 & -1.83 \\
\hline 6 & 1.79 & 17.62 & 2.87 & 20.39 & 3.02 & 3.5 & 1.25 & 0.15 & -1.83 \\
\hline 7 & 1.95 & 18.14 & 2.9 & 24.54 & 3.2 & 2.71 & 1 & 0.11 & -2.21 \\
\hline 8 & 2.08 & 19.25 & 2.96 & 22.79 & 3.13 & 2.62 & 0.96 & 0.11 & -2.21 \\
\hline
\end{tabular}

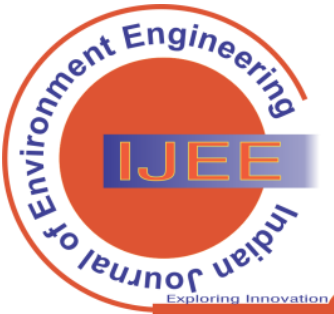


Development of Models for the Rational Design of Different Shapes of Pit Latrine

\begin{tabular}{|c|c|c|c|c|c|c|c|c|c|}
\hline 9 & 2.2 & 18.66 & 2.93 & 21.6 & 3.07 & 2.2 & 0.79 & 0.1 & -2.3 \\
\hline 10 & 2.3 & 25.16 & 3.23 & 23.83 & 3.17 & 2.68 & 0.99 & 0.11 & -2.21 \\
\hline 11 & 2.4 & 25.48 & 3.24 & 24.13 & 3.18 & 2.38 & 0.87 & 0.1 & -2.3 \\
\hline 12 & 2.48 & 19.41 & 2.97 & 24.07 & 3.18 & 1.78 & 0.58 & 0.07 & -2.66 \\
\hline 13 & 2.56 & 22.58 & 3.12 & 22.62 & 3.12 & 1.85 & 0.62 & 0.08 & -2.53 \\
\hline 14 & 2.64 & 25 & 3.22 & 31 & 3.43 & 1.92 & 0.65 & 0.06 & -2.81 \\
\hline 15 & 2.71 & 20.74 & 3.03 & 24 & 3.18 & 1.47 & 0.39 & 0.06 & -2.81 \\
\hline 16 & 2.77 & 30.11 & 3.4 & 28 & 3.33 & 1.85 & 0.62 & 0.07 . & -2.66 \\
\hline & $\begin{array}{l}\sum \ell \mathrm{Np} \\
30.67\end{array}$ & & $\sum \ln V=43.33$ & & $\sum \ell \mathrm{nN}=51.68$ & & $\begin{array}{l}\sum \ell \mathrm{nR} \\
19.08\end{array}$ & & $\begin{array}{l}\sum \operatorname{lnC} \\
-33.09\end{array}$ \\
\hline
\end{tabular}

Table 3 summarized the models derived for the three latrine shapes using data in tables $1-3$.

Table 3: Summary of Derived Models.

\begin{tabular}{|l|l|}
\hline Pit Type & Model \\
\hline Square & $\mathrm{V}=1.01 \mathrm{C}^{1.06} \mathrm{P}^{0.83} \mathrm{~N}^{1.16}$ \\
\hline Circular & $\mathrm{V}=1.03 \mathrm{C}^{0.96} \mathrm{P}^{1.2} \mathrm{~N}^{0.78}$ \\
\hline Rectangular & $\mathrm{V}=0.96 \mathrm{CPN}$ \\
\hline
\end{tabular}

\section{RESULTS AND DISCUSSIONS}

\subsection{Regression Equations}

The summary of the regression equations and coefficients of regression obtained are contained in Table 3.2. The models derived for the three different pit latrine shapes using regression equations and field data from 500 households in the study area using multiple regression equations have been calibrated and verified and found to be better design models when compared with those obtained by other researchers.

\subsection{Comparison between Actual and Derived Pit Volumes}

Figure 4.4 showed the comparison between the derived pit volumes and the actual volumes for the three pit latrines. In all the cases, the derived values were higher than the actual field values. The difference was attributed to the fact that derived values are computed from models calibrated using field data. Models are also standards that should be applicable to similar situations in any part of the world. In this study, latrines surveyed were constructed with local knowledge depending on household choice and financial capability. The difference in the actual and derived volumes was higher in the case of the square and circular pits than in the case of the rectangular pits. This was evident from the values of the correlation coefficients, $\mathrm{R}^{2}$ which was 0.939 for the square pit, 0.959 for the circular pit and 0.990 for the rectangular pits.
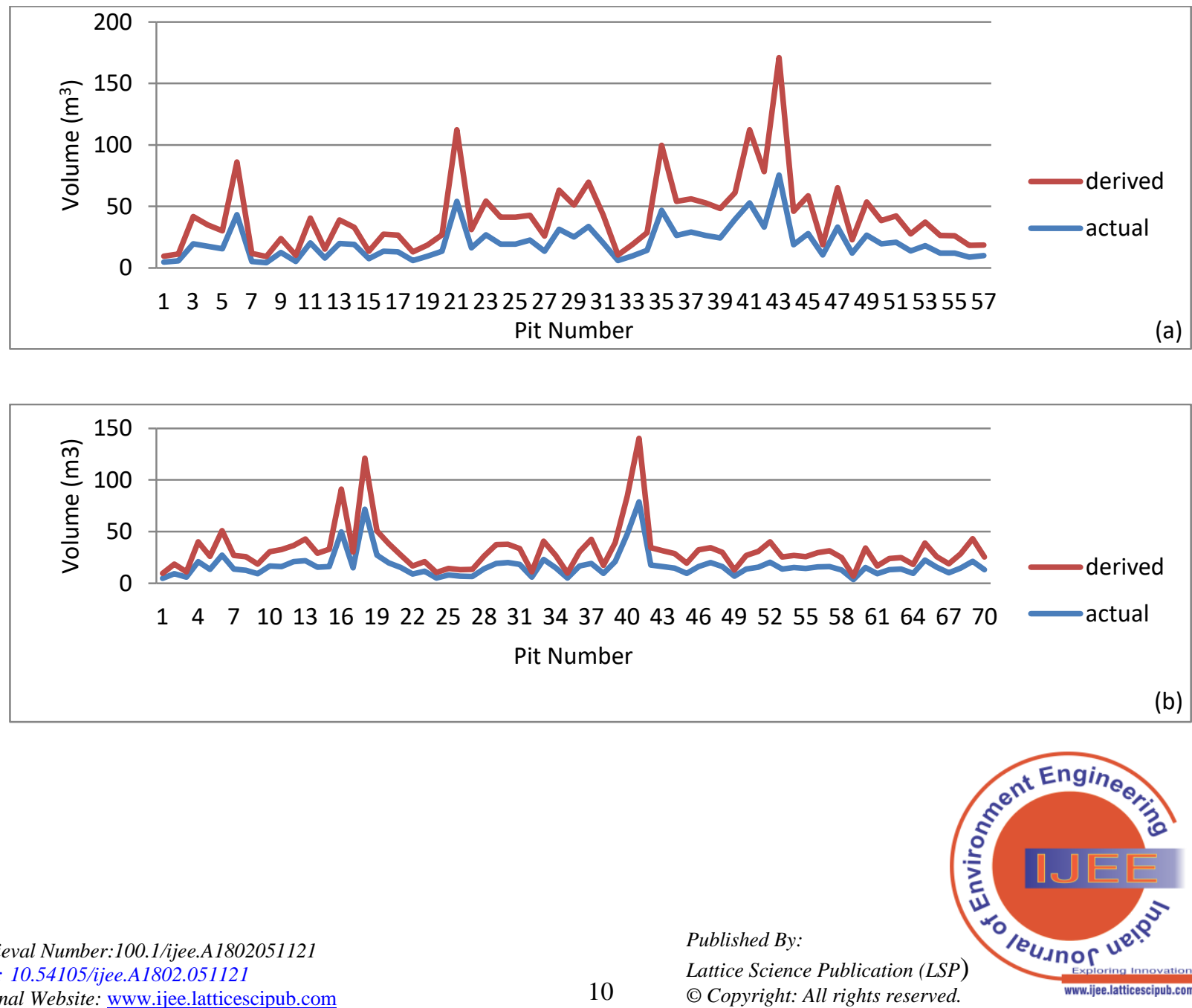


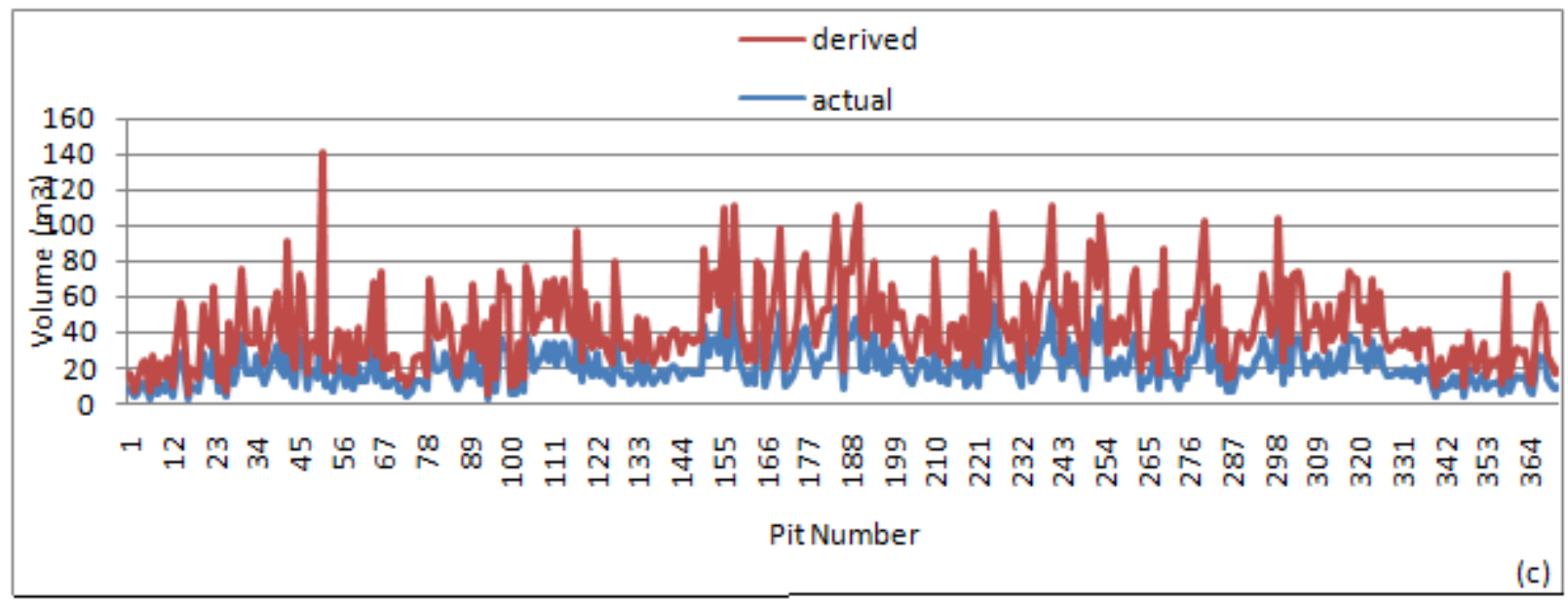

Figure 1: Comparison between Actual and Derived Volumes for (a) square pits (b) circular pits (c) rectangular pits

\subsection{Correlation between Actual and Derived Pit Volumes}

Figure 4.5 showed the relationship between the derived values and the actual values. Both the actual and derived values correlated positively well with correlation coefficient. The correlation coefficient, $\mathrm{R}^{2}$ for the rectangular pit (Figure

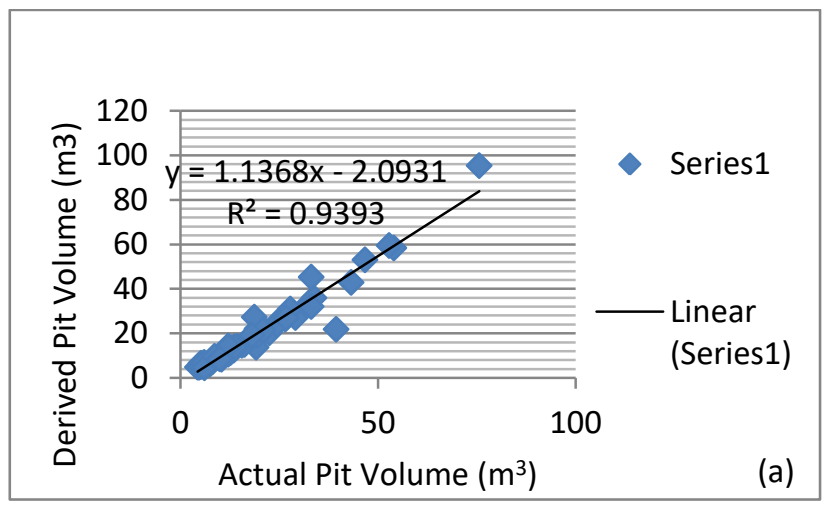

4.5c) was the highest with value 0.990 followed by the circular pit (Figure 4.5b) with the value, 0.959 and lastly the square pit (Figure $4.5 \mathrm{a}$ ) with the value, 0.939. This attested to reliability of the data collected from the field.

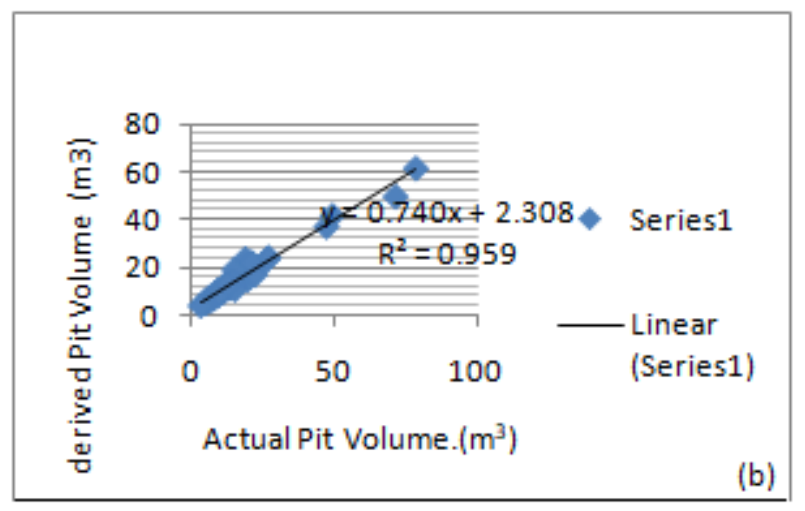

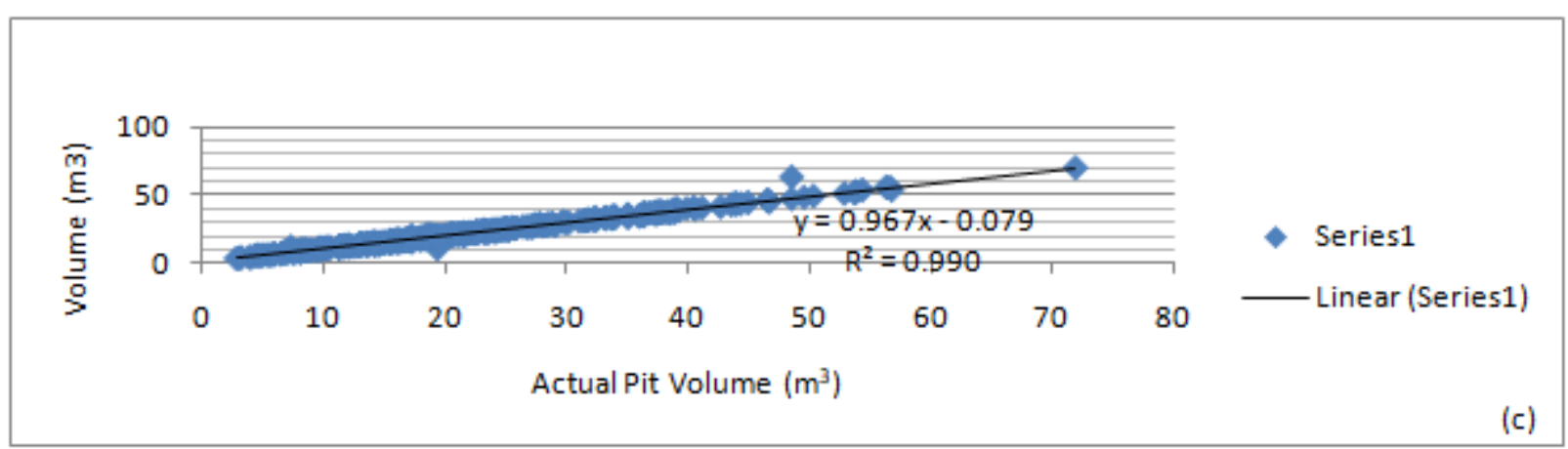

Figure 4.5: Correlation between Actual and Derived Pit Volumes for (a) square (b) circular (c) rectangular pits

\subsection{Calibration of Pit Design Models (Derived and other Models)}

Figure 4.6 showed the calibration of the derived models for the square, circular and rectangular pit latrines. The derived model correlated very well with existing models. For the three pit latrine, the correlation coefficient was 0.941 for this study, 0.953 for that of Oluwafemi and 0.953 for the CASSAD model. In the case of circular pit latrine in Figure 4.6b, the value was 0.955 for this study, 0.996 for that of Oluwafemi and 0.997 for the CASSAD

model. For the rectangular pit in Figure 4.6c, the value was 0.990 for this study, 0.975 for Oluwafemi and 0.966 for CASSAD. The differences in the values could be attributed to the circumstances surrounding the studies such as location and type of latrine surveyed.

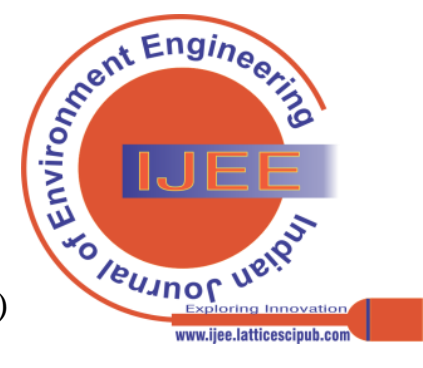




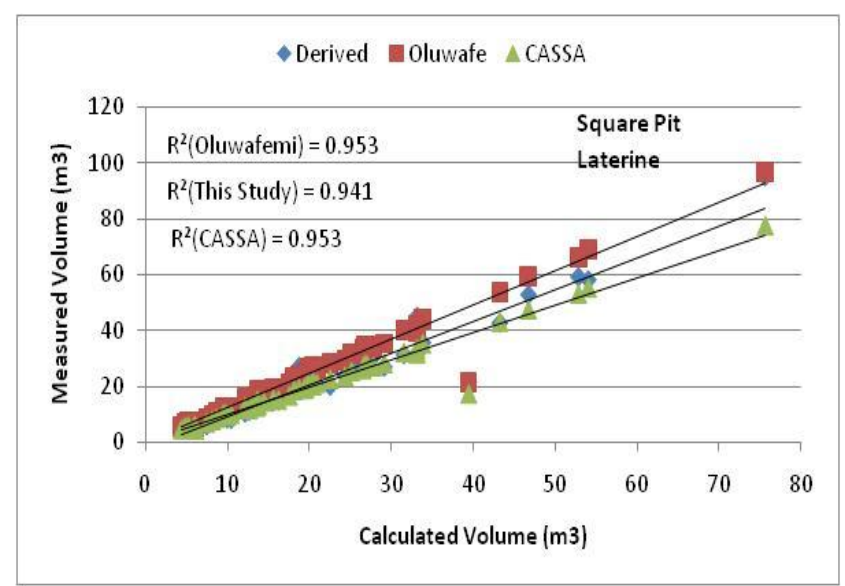

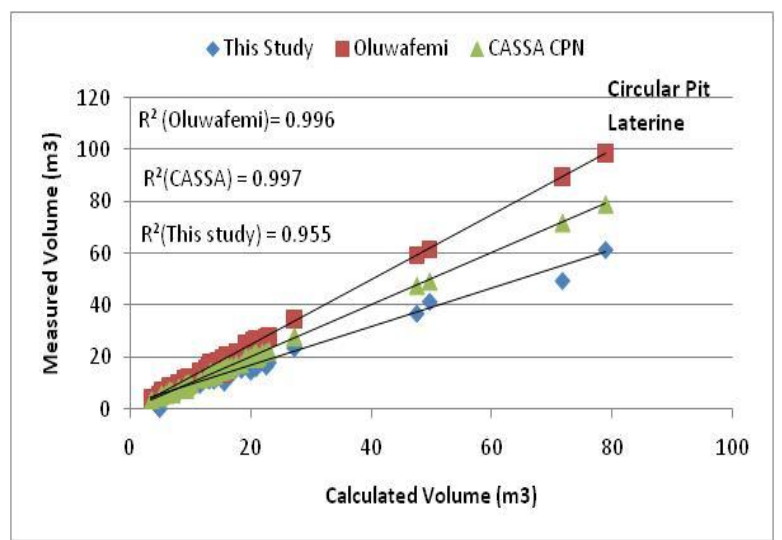

Figure 4.6a: Calibration of Regression Models: Figure 4.6b: Calibration of Regression

For Square pit latrine Models for Circular Pit latrine

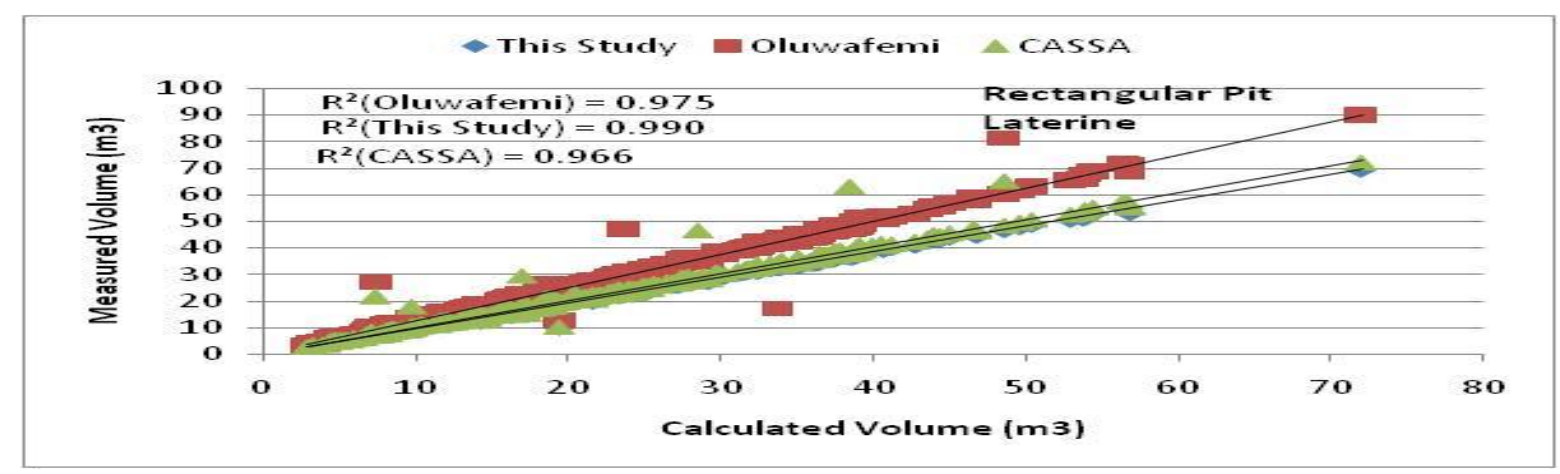

Figure 4.6c: Calibration of Regression Models for Rectangular Pit latrine

\section{CONCLUSIONS AND RECOMMENDATIONS}

\subsection{Conclusions}

This research for the derivation of models for the design of pit latrines of different shapes (namely square, circular and rectangular) has been conducted. Since there were no existing models for the design of different shapes of pit latrine, this study has provided such to enable households construct the type of latrine system they need based on affordability and space available. These models have been verified and calibrated using data collected from the field and they proved to be better than existing models. The effectiveness of these design models is dependent on characteristics of the surrounding soil and ground conditions.

From the above study, the following conclusions were drawn:.

- Models for the rational design of pit latrines of different shapes have been developed and verified based on data collected through questionnaire administration on households. Sample size of 500 households was selected out of about 2, 000 and was a true representative of the community (25\% simple random sampling).

\subsection{Recommendations}

The following recommendations, arising from the outcome of this study, were made:

- Pit latrine design models should not be sophisticated since the users are mostly of rural population and affordability in terms of cost of both materials and labour, availability of space, human resources and logistics should be considered.

- While making use of these models, consideration should be made on the volume and depth of the pit to avoid failure where loose soil exists. In stable soil, the pit depth should be limited to 3 metres only.

\section{REFERENCES}

1. Bhagwan J.N, Still D, Buckley C, Foxon K. (2008). Challenges with Up-Scaling Dry Sanitation. Technologies. Water Sci Technol. 58(1) ; 21-27 [CrossRef]

2. CASSAD (2005). Design of Excreta Disposal for Rural Dwellers.

3. Oluwafemi, B.C.Odediran (1984). Guidelines for the Construction of Ventilated Improved Pit (VIP) Latrines. A Consultancy Document Edited by Lloyd Donaldson, the Chief of WATSAN Section, UNICEF, Lagos. Do It Yourself Manual. United Nations Children Fund and Federal Ministry of Health

4. Wagner, E.G and Lanoix, J.N, 1958. Excreta Disposal for Rural Areas and Small Communities. World Health Organization, Geneva 148.

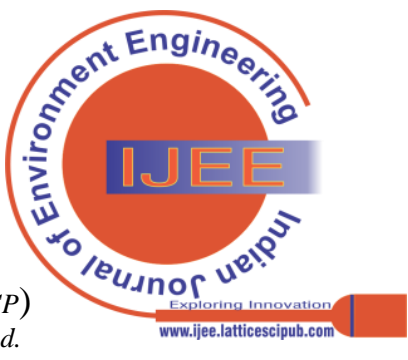

